\title{
Resenha
}

\section{CONNELL, Raewyn; PEARSE, Rebecca. Gênero: uma perspectiva global. São Paulo: nVersos, 2015.}

Fabio de Medina da Silva Gomes ${ }^{1}$

O livro que se apresenta chama-se, originalmente, Gender: In World Perspective. A sua primeira edição foi publicada em 2002, uma outra em 2009, e a terceira em 2015, todas pela Polity Press Ltda., uma editora situada em Cambridge, no Reino Unido. A obra já foi traduzida para 18 idiomas, e tem cumprido o papel de estimular debates sobre os estudos de gênero. (CONNELL, 2015, p. 10). No Brasil, em 2015, foi publicado pela editora paulista nVersos e traduzido por Marília Moschkovich. As autoras são Raewyn Connell e Rebecca Pearse, ambas pesquisadoras australianas vinculadas à Universidade de Sydney.

O prefácio à edição brasileira, de Marília Pinto de Carvalho, trouxe importantes considerações (p. 9-12). Connell tem se destacado com suas contribuições a diversas áreas das humanidades, como Sociologia, Educação, Antropologia e Direito. Os seus estudos sobre masculinidades são conhecidos do público brasileiro; suas pesquisas, no entanto, vão além disso. Ela debate, por exemplo, a ideia de "teorias do sul". ${ }^{2}$ O livro ainda faz uma menção importante à pesquisadora brasileira Heleieth Saffioti, com sua teoria de vanguarda na época, sobre sexo e estratificação social. Esse prefácio ainda

1 Mestre em Direito. Doutorando pelo Programa de Pós-Graduação em Antropologia da Universidade Federal Fluminense. Professor substituto de Direito do Trabalho da Faculdade de Direito da Universidade Federal do Rio de Janeiro (UFRJ). Pesquisador do Instituto Nacional de Ciência e Tecnologia - Instituto de Estudos Comparados em Administração Institucional de Conflitos (INCT-InEAC).

2 Trata-se de uma revisão da relação metrópole e colônia. As autoras pretendem trabalhar através do que se chama de Sul Global, trazendo forma a trazer um ferramental teórico do que se chama de Sul Global. Elas explicam, inclusive, como essas relações de poder influenciam na produção do conhecimento científico. 
lembra da importância desta obra não apenas para os pesquisadores, mas também para os debates públicos, como aqueles relacionados à discussão sobre gênero nas escolas.

A edição brasileira contém uma explicação mais geral sobre alguns termos mais importantes do livro. Algumas dessas expressões são, na verdade, conceitos que encerram um sentido em si mesmos. Destacam-se algumas delas: o primeiro conjunto dessas expressões é "Norte Global, Sul Global, Metrópole e Metrópole Global", referindo-se "à importância e centralidade do período colonial no desenvolvimento da modernidade capitalista" (p. 19). Trata-se de uma referência "aos centros do poder econômico e político herdado do período colonial” (p. 19).

"Pessoas de cor" é outro desses conceitos. A tradutora comenta que optou "por traduzir, literalmente, a expressão utilizada pelas autoras" (p. 20), mas destaca o perigo dessa expressão, tanto no português quanto no inglês. Segundo ela, essa expressão pode ser usada pejorativamente, além de carregar a "falácia de que as pessoas de pele clara não constituem existências sociais racializadas."

"Corporificação" ou "corporificação do social", em inglês "embodiment" ou "social embodiment", é uma ideia central no desenvolvimento do conceito de gênero das autoras: “... esses termos se referem aos processos de absorção corporal das normas e práticas sociais sobre o corpo e seu uso" (p. 21). A tradutora prossegue explicando que, de forma similar, Bourdieu pensava no habitus como uma inscrição no corpo da "das disposições que orientam a ação das pessoas, forjadas pelo arcabouço cultural e simbólico a que tiveram acesso" (p. 21). As autoras pensam num processo de corporificação de gênero para indicar o mesmo caminho nas dinâmicas generificadas.

O livro divide-se em oito capítulos. No primeiro deles, as autoras citam uma grande quantidade de pesquisa para apontar as relações de gênero não apenas como uma diferença, mas como uma desigualdade entre 
homens e mulheres. Afirmam que a expressão gender se tornou comum nos debates na língua inglesa para definir todo um campo de pesquisa.

\begin{abstract}
O termo foi emprestado da gramática. Em última instância vem de um radical que significa 'produzir' (generate/gerar) e que deu origem às palavras que significam "tipo" ou classe" (genus) em diversa línguas. Na gramatica, o "gênero" se tornou uma referência à distinção específica entre classes de substantivos 'que correspondem mais ou menos' - como o Oxford English dictionary do século XIX primeiramente notou - "a distinções de sexo (e a ausência de sexo) nos objetos que se trata. (p. 45)
\end{abstract}

As autoras sublinham que "as palavras para espécies que se reproduzem sexualmente podem ser generificadas, mas também objetos, conceitos e estados mentais." (p. 45). Explica que o inglês é uma língua pouco generificada, mas, na qual, mesmo assim, usa-se "ela" para nomear um navio. Prosseguem mencionando que os debates sobre o tema geralmente se colocam de forma dicotômica, homem e mulher. Elas constroem, desse modo, a ideia de uma ordem de gênero, apontando a falha nessa divisão, sendo essa ordem por demais simplista para explicar uma realidade total. Uma das grandes contribuições das autoras é pensar gênero não como uma relação entre homens e mulheres, mas como um construto relacional. Gênero é assim uma estrutura social, envolvendo uma relação específica com os corpos. Ele é multidimensional, ou seja, diz respeito ao trabalho, à identidade, ao poder e a tudo ao mesmo tempo.

\footnotetext{
Agora nos é possível definir 'gênero' de forma a resolver os paradoxos sobre a 'diferença' O gênero é a estrutura das relações sociais que se centra sobre a arena reprodutiva e o conjunto de práticas de que trazem as distinções reprodutivas sobre os corpos para o seio dos processos sociais. (p. 48)
}

No capítulo dois, elas discutem cinco estudos das últimas décadas sobre gênero. Demonstram "a diversidade das dinâmicas de gênero, sua complexidade e seu poder" (p. 84), afirmam que "as dinâmicas de gênero operam em muitas esferas que não são tipicamente rotuladas como questões 
de gênero, como o ambientalismo ou a guerra". (p. 84) Trata-se de uma reunião de importantes pesquisas de cunho empírico sobre gênero em diferentes situações sociais (p. 84)

"Diferenças sexuais e corpos generificados" foi o título dado ao terceiro capítulo. Tendo já explicado o debate sobre a definição do conceito de gênero, elas debatem mais detidamente a ideia de corporificação social para reconhecer um aspecto do gênero. "Muitos processos de gênero envolvem processos corporais e capacidade que não são, em si mesmos, diferenciados por gênero, sendo, de fato, capacidades comum a mulheres e homens" (p. 117). Citam como exemplo a "capacidade de trabalho numa economia industrial" (p. 117). As diferenças, nesse caso, advém de um treinamento, pelo tratamento da gravidez como deficiência ou mesmo por conta de determinado desenho generificado dos equipamentos de trabalho.

Em seguida, estudam algumas teorias de gênero. Trata-se, com certeza, da parte mais teórica do livro. Mencionam vários teóricos sobre o assunto. Sua ênfase na contemporaneidade é marcada por duas teorias, a teoria queer e a pós-colonial. Explicam a centralidade dos estudos empreendidos por Butler para a primeira teoria e filiam-se à ultima, a de cunho pós-colonial. Connell e Pearse não economizaram autoras do chamado Sul Global para construir sua teoria. Não apenas Saffioti foi uma das teóricas lembradas, mas também outras, algumas ainda desconhecidas do público brasileiro. Entre elas estão a indiana Bina Agarwal, a nigeriana Amina Mama, a libanesa Mai Ghoussoub e a sul-africana Jane Bennett. Toda essa teoria vai afastar-se de uma homogeneização vinda das teorias da metrópole.

O quinto e o sexto capítulos são complementares, inter-relacionandose em diversos pontos. Entender gênero, tanto na vida política quanto na vida pessoal, requer certa sensibilidade. Nessas páginas, as autoras enfrentam diversas discussões, como, por exemplo, a questão dos transgêneros e transexuais. Enquanto isso, nos capítulos sete e oito são tratados problemas 
ligados à mudança ambiental e à economia. Elas relacionam esses assuntos com os problemas levantados por seus estudos de gênero.

Já nas considerações finais, ressaltam que o livro procurou uma compreensão do impacto do gênero, tanto na vida pessoal quanto em "âmbitos local e global" (p. 287). Registram que muitas feministas têm se valido dessa literatura para criticar a "ordem de gênero", enfrentando questões difíceis relativas à sexualidade, à raça ou à classe. (p. 288) $\mathrm{E}$ terminam com a seguinte assertiva:

Como o feminismo descobriu, o conhecimento sobre o gênero precisa ser reconsiderado de novo e de novo, à luz das dinâmicas mutantes de gênero encontradas na política mundial de gênero. Dada essa vontade de aprender, estamos convencidos de que a teoria de gênero e a pesquisa podem ter um papel significativo na construção de um mundo mais democrático. (p. 289)

Como mencionado no início, o leitor brasileiro apenas teve acesso a esse livro em português em 2015. Trata-se de uma obra importante para reflexões em diversa áreas do conhecimento. O cientista social precisa compreender a ordem generificada dos processos de corporificação. Os profissionais de educação precisam levar esse debate para a sala de aula. E o jurista precisa dessas ferramentas teóricas para melhor entender a realidade social envolvendo transfobia, violência de gênero, o acesso ao mercado de trabalho, desigualdade de gênero, homofobia e outras tantas problemáticas mais contemporâneas. Cuida-se aqui de um livro recomendado para todos que querem pensar gênero por meio de teorias póscoloniais. 